REVIEW

This paper is dedicated to the $70^{\text {th }}$ anniversary of the founding of Physiologia Bohemoslovaca (currently Physiological Research)

\title{
Aspiration Syndromes and Associated Lung Injury: Incidence, Pathophysiology and Management
}

\author{
Petra KOSUTOVA ${ }^{1}$, Pavol MIKOLKA ${ }^{1}$ \\ ${ }^{1}$ Biomedical Center Martin and Department of Physiology, Jessenius Faculty of Medicine in \\ Martin, Comenius University in Bratislava, Martin, Slovakia
}

Received September 20, 2021

Accepted November 5, 2021

\section{Summary}

Aspiration is a common condition affecting healthy or sick patients which could create an acute or chronic inflammatory reaction in the lungs. Aspiration syndromes could be categorized according to a content entering the respiratory system into bacterial aspiration pneumonia with the gastric or oropharyngeal bacteria entering, aspiration chemical pneumonitis with bacteriafreegastric acid aspiration, or aspiration of a foreign body which causes an acute pulmonary emergency. There are differences in the clinical presentation of volume-dependent aspirations (microaspiration and macroaspiration): the higher is the volume of aspiration, the greater is the injury to the patient and more serious are the health consequences (with $70 \%$ mortality rate for hospitalized patients). Aspiration syndromes can affect both the airways and pulmonary parenchyma, leading to acute lung injury, increased hospitalization rate and worse outcomes in critically ill patients. Impaired alveolar-capillary permeability, oedema formation, neutrophilic inflammatory response and pulmonary surfactant inactivation lead to reduced lung compliance and loss of aerated lung tissue and give rise to hypoxemia and respiratory failure. This review discusses the effect of aspiration events on the pulmonary tissue. The main focus is to distinguish the differences between bacterial and chemical pneumonia, their clinical presentation and symptoms, risk factors of developing the changes, possibilities of diagnostics and management as well as prevention of aspirations. Because of a risk of serious lung damage after the aspiration, pathophysiology and processes leading to lung tissue injury are discussed in detail. Data sources represent a systematic literature search using relevant medical subject headings.

\section{Key words}

Aspiration syndromes - Aspiration pneumonitis - Aspiration pneumonia • Acute lung injury • Pathophysiology

\section{Corresponding author}

Pavol Mikolka, Biomedical Center Martin and Department of Physiology, Jessenius Faculty of Medicine in Martin, Comenius University in Bratislava, Mala Hora 4C, SK-03601 Martin, Slovakia. E-mail: pavol.mikolka@uniba.sk

\section{Introduction}

Aspiration represents a great danger for patients. In aspiration, a material, either liquid or even a foreign object passes from the mouth or the upper part of the gastrointestinal tract into the lungs. Aspiration syndromes occur more frequently than reported, in many cases, the disease is not recognized (unwitnessed). Aspiration symptoms are classified based on three main characteristics: infectiousness of the inoculum, its volume, and acuity of the onset of the clinical syndrome (Son et al. 2017).

Aspiration pneumonitis and aspiration pneumonia are two important manifestations of macroaspiration that cause abrupt changes in the patients' conditions (Marik 2001). The most affected are hospitalized and critically ill patients where the mortality rate could be $70 \%$ in large volume and low $\mathrm{pH}$ aspirates (DeLegge 2002, DiBardino and Wunderink 2015). The aspiration syndromes can be difficult to distinguish. Clinical presentation and disease management are 
affected by various variables, such as bacterial virulence, risk of repeated events, and the site of acquisition (nursing home, hospital, or community) (Mandell and Niederman 2019). They also differ in terms of providing the appropriate treatment for each of the conditions. In addition, aspiration syndromes are recognized as an independent risk factor for the subsequent development of acute respiratory distress syndrome (ARDS), a life-threatening condition characterized by diffuse lung damage, inflammation, oedema formation, and surfactant dysfunction leading to respiratory failure (Mokrá 2020, Raghavendran and Napolitano 2011, Zaloga 2002).

We systematically searched NCBI, Scopus, Web of Science, and Cochrane Library databases of 'aspiration pneumonia, aspiration pneumonitis, ARDS, acute lung injury' from inception to 14 July 2021. Data sources included scientific reviews and original research publications from the human and veterinary literature. All reviews and studies that added some information to the understanding of aspiration syndromes were included. Finally, we aimed to summarize a current evidence surrounding the clinical presentation, pathophysiology, diagnosis, treatment, risks and prevention of aspiration syndromes.

\section{Pulmonary aspiration syndromes}

Pulmonary aspiration, which is defined as the misdirection of oropharyngeal or gastric contents into the larynx and lower respiratory tract, can be a dangerous phenomenon (Marik 2001). Various materials can be aspirated, such as bacteria, nasal secretions or saliva, toxic substances, liquids and food, or gastric contents (Son et al. 2017, Zaloga 2002). Aspiration syndrome occurs more frequently than is recorded, and the disease is often misdiagnosed. In hospitalized and institutionalized patients with predisposing disorders, early detection of this complication and efficient preventive measures will considerably minimize the severity of health complications and mortality associated with aspiration syndromes (Petroianni et al. 2006). Aspiration syndrome may occur due to (1) airway syndromes such as chronic cough, exacerbation of asthma/bronchospasm or bronchiolitis obliterans in lung transplantation, (2) lung parenchymal syndromes such as exacerbation of fibrotic lung disease or aspiration pneumonitis, (3) bacterial pneumonia such as community or hospital-acquired, ventilator-associated or aspiration pneumonia (Son et al. 2017). However, only bacterial types of pneumonia and acute circumstances are infectious. The summary is shown in Table 1.

There are three particular classifications of aspiration syndromes that are pathologically and clinically distinct: (1) Foreign body aspiration (FBA), (2) Aspiration pneumonitis, (3) Aspiration pneumonia (Paintal and Kuschner 2007).

Table 1. Aspiration syndromes (adapted from Sun et al. 2017).

\begin{tabular}{cccc}
\hline & $\begin{array}{l}\text { Infectious } \\
\text { inoculum }\end{array}$ & Volume & Acuity of onset \\
\hline AIRWAY SYNDROMES & & & \\
- Chronic cough & No & Micro & Chronic \\
- Exacerbation of asthma/bronchospasm & No & Micro & Acute/subacute \\
- Bronchiolitis obliterans in lung transplantation & No & Micro & Chronic \\
LUNG PARENCHYMAL SYNDROMES & No & Micro & Chronic \\
- Exacerbation of fibrotic lung disease & No & Macro & Acute \\
- Aspiration pneumonitis & Yes & Micro & Acute \\
BACTERIAL PNEUMONIA & Yes & Variable & Acute \\
- Community-acquired & Yes & Micro & Acute \\
- Hospital-acquired & Yes & Macro & Acute \\
- Ventilator-associated & & & \\
\hline
\end{tabular}




\section{Foreign body aspiration}

Infants and toddlers are most likely to suffer from the foreign body aspiration (FBA) which mechanically blocks the airways and causes asphyxiation (Marraro et al. 2007, Paintal and Kuschner 2007). In adults, higher risk of foreign body asphyxiation syndrome may be observed in patients with impaired sensory capacities, craniofacial trauma, loose teeth, or dental appliances (Umesan et al. 2012). The typical presentation of tracheobronchial blockage resulting from aspiration includes a history of eating or swallowing followed by an abrupt onset of difficult speaking or breathing.

Common signs and symptoms of FBA include tachypnoea, tachycardia, wheezing, cough, and cyanosis (Paintal and Kuschner 2007). The Heimlich manoeuvre is used to manage foreign object asphyxiation (Montana et al. 2020) or the other procedures should be rapidly used to clear the airways. This is an urgent situation because in complete blockade of the trachea, there are only 3 to 5 minutes to restore the airway, otherwise there is a risk of ischemia damage to the brain, heart, and other essential organs that cannot be reversed (Stubington and Kamani 2021). Treatment options represent an extraction of the foreign object using a rigid bronchoscope or flexible fiberoptic laryngoscope (Ibrahim Sersar et al. 2005, Rafanan and Mehta 2001).

FBA is a rare but potentially fatal complication that occurs in $0.16-0.33 \%$ of adult bronchoscopic procedures (Sehgal et al. 2015), and is slightly more common in males (Limper and Prakash, 1990, Sehgal et al. 2015). The vast majority of adult patients with FBA has obvious risk factors for aspiration including neurological deficits with swallowing difficulties or altered mental status, neuromuscular disease, intoxication, or has an iatrogenic cause. Adult FBA typically presents with choking followed by persistent coughing, but when the first event goes unnoticed, it might mimic more chronic diseases such as COPD, asthma, and obstructive pneumonia (Boyd et al. 2009, Limper and Prakash 1990, Lin et al. 2014, Sehgal et al. 2015). Wheezing, dyspnea, hemoptysis, chest discomfort, and recurrent pneumonia are some of the less common symptoms. The size of the FB and the area in which it becomes lodged define the symptoms. Impaction in the trachea leads to a more dramatic presentation of inspiratory stridor with frequent coughing, while occlusion of the lower bronchi can result in coughing, wheezing, dyspnea, or hemoptysis, and may be mistaken with an alternative diagnosis (Dikensoy et al. 2002).

\section{Aspiration pneumonitis}

Aspiration pneumonitis is defined as an acute lung injury (ALI) caused by macroaspiration of refluxed gastric contents (Son et al. 2017). Aspiration of gastric contents causing a chemical pneumonitis characterized by fever, cyanosis, hypoxia, pulmonary oedema, and potential death was initially described as "Mendelson syndrome" (Salik and Doherty 2021). However, the contents of the stomach include not only acidic fluid but also food particles. Animal experiments showed that administration of small non-acidified gastric particles (SNAP) into the trachea induced acute neutrophilic lung inflammation $r$ within 4 to 6 hours, without any direct lung injury in the early phases (Knight et al. 1993). However, the combination of SNAP and acid was found to be in close resemblance to the gastric aspiration, with more severe changes observed in comparison with lung injuries due to acid or SNAP alone (Davidson et al. 2005, Son et al. 2017).

The gastric contents are sterile under normal conditions. However, the change in gastric fluid $\mathrm{pH}$ creates an environment in which the potentially pathogenic microorganisms become viable. For instance, gram-negative bacteria may cause a gastric colonization in patients who are fed enterally, in patients with gastroparesis or with small-bowel blockage [47, 48]. When gastric aspiration occurs in those circumstances, a lung infection may develop as a result of the bacteria present in the gastric contents, indicating how pneumonitis can overlap with aspiration pneumonia (Son et al. 2017).

The pathophysiology of aspiration pneumonitis. The majority of aspirates in the clinical scenarios are liquid whereas the extent and progression of the injury to the pulmonary parenchyma are determined by the nature of the aspirate. The inflammation is a result of the chemical burn assuring to the mucosa of the trachea, bronchi and parenchyma of the lungs, due to the toxicity of $\mathrm{pH}$ of the gastric aspirate (Hunt et al. 2018). While in normal conditions, macrophages are important in the first defence line, the acidic environment of the stomach decreases activity of the macrophages. This further reduces a bacterial destruction and increases a risk of developing aseptic respiratory tract infections after gastric content aspiration, (Heming et al. 2001).

Generally, two clinical phases of pneumonitis can be distinguished (Raghavendran et al. 2011). The first phase is defined by intense coughing or 
bronchospasm that occur immediately after the aspiration incident, characterized by stimulation of capsaicinsensitive neurons and direct caustic actions of low $\mathrm{pH}$ on airway epithelium. The second phase is characterized by the onset of neutrophil-induced pulmonary inflammation during the next 4-6 hours (Kennedy et al. 1989). The longer is the acidic content in contact with the respiratory tract, the more potent is the alteration of the immune system (Hackett et al. 2016). Exposure to low pH of gastric content leads to a loss of pulmonary microvascular integrity, resulting in fluid and protein extravasation into the airways and alveoli (Raghavendran et al. 2011). Plasma proteins and other components of oedema fluid can directly interfere with the function of alveolar surfactantwhat increases the breathing effort due to increased airway resistance and decreases a diffusion of oxygen.

Gastric aspiration triggers an inflammatory cellular response. Low $\mathrm{pH}$-mobilized and activated neutrophils release histamine, leukotrienes and TGF- $\beta$ which affect the surfactant integrity of the alveoli and contribute to respiratory insufficiency (Reeves et al. 2002). There have been several local and systemic inflammatory mediators identified to have a role in acidinduced lung injury (Goldman et al. 1993). Specifically levels of proximal proinflammatory cytokine, tumor necrosis factor (TNF)- $\alpha$ (Davidson et al. 1999), neutrophil chemotactic chemokine interleukin (IL)-8 (Folkesson et al. 1995), macrophage inflammatory protein-2 (MIP-2) (Shanley et al. 2000) and cytokineinducted neutrophil chemoattractant-1 (CINC-1) are elevated in the bronchoalveolar lavage (BAL) fluid (Knight et al. 2004). In addition, increases in leukocytederived oxidants and proteinases (Raghavendran et al. 2011) and activation of complement participate in the systemic response of acid-induced lung injury (Nishizawa et al. 1996). Besides epithelial damage, neutrophils themselves cause endothelial cell injury via inhibition of NADPH oxidase. Both pepsin and bile salts also activate the effect of IL-8 causing a direct damage, and via stimulation of neutrophilic influx induce an endothelial cell injury (Brinkmann et al. 2004).

Dysfunction of pulmonary surfactant in acid aspiration pneumonia was confirmed in experiments where treatment with exogenous surfactant improved a pulmonary function, but only when inhibitory plasma proteins were removed by a lavage (Davidson et al. 2005, Eijking et al. 1993).

\section{Aspiration pneumonia}

Aspiration pneumonia is a process of proliferation and invasion of pulmonary parenchyma caused by the inhalation of oropharyngeal secretions that are colonized by pathogenic bacteria (Almirall et al. 2021). Pneumonia can be induced by aspiration of infectious content from the upper airways orthe oral cavity, or in more serious cases the bacteria can enter the lungs via hematogenous spread from other locations (Cabre et al. 2010).

While previously the most prominent types of bacteria present in aspiration pneumonia were the anaerobic bacteria (Mandell and Niederman 2019), nowadays there has been a shift in the observed types of microorganisms (Bartlett, 2013). Main types of bacteria in a community-acquired pneumonia are Streptococcus Pneumoniae, Staphylococcus Aureus, Haemophilus Influenza, and Enterobacteria, whereas a hospitalacquired pneumonia is usually caused by gram-negative enteric bacteria, such as Pseudomonas Aeruginosa (Rotstein et al. 2008). In patients suffering from gastrointestinal disorders, the gram-negative Enterococci are often detected (Mandell and Niederman 2019). However, in small burden of bacteria in the oropharyngeal secretion, good coughing mechanisms along with the patient's cellular and humoral immune systems, and active ciliary clearance, may prevent an infection of the lung after the aspiration. Nevertheless, any impairment of these mechanisms accompanied by abundant aspiration may result in aspiration pneumonia (Dickson et al. 2013).

The pathophysiology of aspiration pneumonia cannot be understood in the absence of bacteriological investigation. It's critical to distinguish aseptic aspiration pneumonitis, in which the damage to the pulmonary tissue is caused by acidic gastric material rather than bacteria, from bacterial aspiration pneumonia (Mandell and Niederman 2019). In addition, varying frequency, volume, and particle size result into a wide array of changes, which are similar to the pathophysiology of ARDS (Neill and Dean 2019).

The microbiological aetiology of aspiration pneumonia may depend on different aspects. For instance, the type of pathogen in community-acquired pneumonia is influenced by age, smoking habits, alcohol abuse, and comorbidities such as COPD, diabetes mellitus, liver disease, renal failure, and neurological illness (Almirall et al. 2021, Liapikou et al. 2014). 
Chronic and frequent aspiration contributes to pneumonia because of denuded epithelium and increased pool of bacteria in the lungs (Neill and Dean, 2019).

The pathophysiology of aspiration pneumonia can be explained as the combination of risk factors that alter swallowing function, cause aspiration, and predispose the oropharynx to bacterial colonization (Ortega Fernández and Clavé 2013). The pathological changes occur when the normal defense mechanisms, i.e. the mucociliary transport and alveolar macrophages acting in clearing microaspirations, fail in a predisposed individual. Entrance of aspirate with common flora organisms from the oropharynx and oesophagus into the bronchi and alveolar space triggers the production of proinflammatory cytokines, $\mathrm{TNF}-\alpha$, and interleukins (Sanivarapu and Gibson 2021).

Aspiration syndromes are recognized as an independent risk factor for the subsequent development of ARDS (Mokrá, 2020, Raghavendran et al. 2011, Son et al. 2017). Macrophages, alveolar cells, immune effector cells, and neutrophils, as well as platelets and monocytes are critical in defending the lung and play key roles in acute lung injury (ALI) induced by aspiration syndromes (Matthay et al. 2019).

The lung injury is associated with an accumulation of protein-rich oedema fluid in the interstitium and the distal air spaces (Fanelli et al. 2013). Conceptually, increasing lung vascular permeability can occur because of a breakdown of endothelial junctions or a death of endothelial cells. Endothelial cell activation results to generation of mediators, such as angiopoietin-2, and leukocyte accumulation. Endothelial cell activation results into neutrophil-platelet interaction. Neutrophilplatelet aggregates seem to play a synergistic role in causing an increase in lung vascular permeability to protein (Huppert et al. 2019, Kosutova et al. 2019). Migration and activation of neutrophils into the lung lead to subsequent degranulation and release of toxic mediators, such as proteases, reactive oxygen and nitrogen species, pro-inflammatory cytokines, and pro-coagulant molecules (Mikolka et al. 2021, 2019). This causes diffuse inflammatory reaction, pulmonary surfactant inactivation, and reduced lung compliance. Ventilation-perfusion mismatch and increased physiological dead space give rise to hypoxemia, which further affects a lung function in the early phase after aspiration (Kane-Gill et al. 2007).

\section{Risk factors of aspiration syndromes}

When aspiration occurs, two specific factors have been identified as causal: (1) lost or reduced protective reflexes when the individual's consciousness has undergone ageing-related alteration, (2) impairments of neuromuscular function (Marik and Kaplan, 2003). There are additional contributing factors that put the older adult at risk for aspiration, including use of sedatives, drug abuse, dementia, use of alcohol, metabolic disorders, traumatic brain injury, stroke, seizures and any type of therapeutic or diagnostic procedures that involve the upper thorax or the oesophagus (Huxley et al. 1978, Langmore et al. 1998, Marik and Kaplan 2003).

The clinical signs of an aspiration incident range from subclinical symptoms like dry cough or dysphonia to life-threatening disorders such as ARDS. Secondary infection, lung abscess, airway obstruction, exogenous lipoid pneumonia, and progression into chronic interstitial fibrosis can all aggravate the pathogenic process (Marik 2001). Patients with low gastric $\mathrm{pH}$, decreased gastroesophageal sphincter tone, or elevated gastric pressure are also at risk, as well as the other predisposing factors such as sepsis, pregnancy, and nutrition (Raghavendran et al. 2011).

The risk factors for aspiration of a large volume are: (1) altered state of consciousness: sedation, traumatic brain injury, encephalopathy, seizure disorder, poisoning, alcohol/drug intoxication, (2) gastrointestinal disorders: gastroesophageal reflux, gastroparesis, bowel obstruction/ileus, oesophagal motility disorders: primary - achalasia, oesophagal stricture, secondary scleroderma, polymyositis, (3) compromised gag reflex: endotracheal intubation, bulbar paralysis, enteral tube feeding, (4) dysphagia/swallowing dysfunction: stroke, dementia, chronic obstructive pulmonary disease (COPD), Parkinson's disease, (5) obesity, and (6) labor (Raghavendran and Napolitano 2011, Son et al. 2017). Risk factors for aspiration syndromes are listed in Table 2.

\section{Microaspiration and macroaspiration}

The amount of aspirated material also belongs to the risk factors for aspiration. Microaspiration represents smaller amounts of reflux material when the microbes are seeded into the lower airways most often in the form of oropharyngeal secretions. It occurs even in healthy individuals and to cause a disease, it requires 
a compromise in the defensive systems (Segal et al. 2014). Higher prevalence of microaspiration may be found in asthma, COPD, sleep apnea of the obstructive type, atypical lung infections and cystic fibrosis (CF) where along with an acid reflux the coordination of breathing and swallowing (Miller et al. 2005) and clearance of microorganisms from the lower airways (Randell and Boucher 2006) are reduced.

Table 2. Risk factors for aspiration syndromes

\begin{tabular}{c}
\hline ALTERED STATE OF CONSCIOUSNESS \\
\hline - Sedation \\
- Traumatic brain injury \\
- Encephalopathy \\
- Poizure disorder \\
- Alcohol/drug intoxication \\
\hline
\end{tabular}

\section{GASTROINTESTINAL DISORDERS}

- Gastroesophageal reflux

- Gastroparesis

- Bowel obstruction/ileus

- Oesophagal motility disorders

- Prim: Achalasia, Esophageal stricture

- Sec: Scleroderma, Polymyositis

\section{COMPROMISED GAG REFLEX}

- Presence of endotracheal intubation

- Bulbar paralysis

- Enteral tube feeding

\section{DYSPHAGIA / SWALLOWING DYSFUNCTION}

- Stroke

- Parkinson's disease

- Dementia

- Chronic obstructive pulmonary disease

\section{OBESITY}

\section{LABOUR}

Macroaspiration occurs when a large volume of particles is inhaled into the lungs, most commonly after impairment of protective reflexes, e.g., in neurodegenerative diseases or drug overdose (Son et al. 2017). Macroaspiration can also occur as a result of aberrant swallowing mechanics or when swallowing is hampered by CNS dysfunction, allowing stomach or oesophagal contents to enter the lungs. Increased risk of macroaspiration have been also linked to dementia and taking of sleeping pills (Mandell and Niederman 2019). Development of aspiration pneumonia is a frequent consequence of cardiopulmonary resuscitation due to cardiac arrest, in which the gastric content may enter the lungs. Pneumonia developed within 3 days after the event in $65 \%$ of the patients (Perbet et al. 2011). In addition, larger volume aspiration can occur when a patient has cancer of the neck, head, or oesophagus, dysphagia, or limited motility of the oesophagus, or in COPD or seizures (Mandell and Niederman 2019).

Macroaspiration could result into ALI (Mokrá, 2020). The severity of clinical presentation of macroaspiration and microaspiration differs according to aspirated volume so that higher is the volume of the aspiration, the greater is the injury to the patient and the more serious are the health consequences (Neill and Dean 2019). Bacterial pneumonia as a secondary impact was developed in $25 \%$ of patients who had macroaspiration and pneumonitis. However, only some therapies can be used for treating macroaspiration. Antibiotic therapy given when aspiration pneumonia is apparent after a macroaspiration event was found to be more efficacious than prophylactic antimicrobial therapy in individuals with acute aspiration pneumonitis (Dragan et al. 2018, Kane-Gill et al. 2007). This knowledge allow the specialists to spend less time implementing the wrong treatment based on the situation being assessed (Grieco et al. 2021).

\section{Incidence and epidemiology of aspiration syndromes}

Most aspiration events go undetected or unnoticed, as it is difficult to suggest commonness and abundance of pneumonia caused by aspiration, both micro and macro-aspiration. In up to $64 \%$ of aspirations during anaesthesia, clinical or abnormal radiological signs were not detected (Raghavendran et al. 2011). There are a few studies available describing an aspiration as a cause of community-acquired pneumonia. Aspiration pneumonia accounts for 5 to $15 \%$ of cases of community-acquired pneumonia (Marik 2001), however, data on hospital-acquired pneumonia is unavailable (Mandell and Niederman 2019). Aspiration was found in 4 to $26 \%$ of pneumonia episodes in a survey of more than 1 million patients in more than 4200 hospitals.

Patients with aspiration pneumonia have higher predicted mortality than those with other types of pneumonia, and a risk-adjusted mortality, used as 
a quality metric, is lower in hospitals reporting a high frequency of aspiration than in hospitals reporting a low frequency of aspiration (Lindenauer et al. 2018). General anesthesia is a well-known reason for gastric aspiration that affects one out of every two to three thousand patients (Marik 2001, Raghavendran et al. 2011, Warner et al. 1993). In reality, it has been observed that aspiration occurs in roughly 3 out of every 10,000 anaesthetized patients, more frequently in special groups and emergency settings (Abdulla, 2013), such as trauma and/or intensive care unit (ICU) patients with altered states of consciousness (e.g., head trauma, alcohol or drug-induced sensoric alterations, cerebrovascular accidents) and/or disabled patients (Aldridge and Taylor, n.d.) and/or elderly patients, and nursing home residents (Mylotte et al. 2003a). According to a prospective study that used the level of pepsin in BAL as a surrogate marker of aspiration in ICU patients, $88.9 \%$ of the patients had at least one aspiration episode (Metheny et al. 2006).

Unwitnessed gastric aspiration may explain many cases of perioperative pulmonary dysfunction (Marik 2001, Mylotte et al. 2003b). The ability to distinguish between the two most common presentations of aspiration syndromes, inflammatory lung injury with aspiration pneumonitis and bacterial aspiration pneumonia, is a challenging task. In addition, the severity of lung injury after aspiration varies according to the amount, composition, and acidity of aspirate, as well as patient-specific features (Son et al. 2017).

The severity of a lung injury following gastric aspiration ranges from a mild, subclinical pneumonitis to a progressive respiratory failure with significant morbidity and mortality. Larger aspirated volume can lead to severe complications and a third of patients with aspiration pneumonitis develop a more severe and protracted course that is subsequently linked to ARDS (Raghavendran et al. 2011, Warner et al. 1993). Patients who present with several risk factors, such as higher age, have an increased risk of aspirating and developing pneumonia or pneumonitis. When other forms of community-acquired pneumonia are compared to aspiration pneumonia, the mortality rate in aspiration pneumonia is substantially higher, with $29.4 \%$ versus $11.6 \%$, a finding that could imply hospitals that fail to correctly register its presence (Lindenauer et al. 2018, Mandell and Niederman 2019). ARDS linked with aspiration pneumonitis has a $30 \%$ mortality rate and is responsible for up to $20 \%$ of all anaesthesia-related deaths (Nason 2015). Aspiration is also associated with dysphagia, a common and major risk factor that raises mortality rates by 4.69 times in stroke patients (Feng et al. 2019).

\section{Clinical presentation, diagnosis and assessment of aspiration syndromes}

While macroaspiration is an important feature in aspiration pneumonia and chemical pneumonitis, it is almost impossible to estimate the degree of the exposure because are so uncommon. There is a wide variety of clinical presenting features, from no symptoms to severe discomfort and respiratory failure (Calkovska et al. 2019, Mandell and Niederman 2019) which can develop as acute or subacute, and may follow in a progressive or even more progressive manner. Pulmonary aspiration may impact the airway and/or the lung parenchyma. Aspiration pneumonia is usually acute, and symptoms appear fastly, usually within hours or just a few days after the event (Hollaar et al. 2016). However, in less aggressive bacteria, anaerobic aspiration can be subacute, and clinical symptoms might be difficult to identify from those of other bacterial pneumonia (Mandell and Niederman 2019). It is important to note that when there is a pulmonary aspiration, patients can also have a chronic cough, asthma attack, or bronchospasm. It is problematic to distinguish between chemical aspiration and other types of aspiration (aspiration pneumonia and aspiration of bland material) because of the event being unwitnessed (Mandell and Niederman 2019). A solid FB may block the airways, resulting in pneumonia and making it difficult to distinguish from bacterial pneumonia. In a study of patients over 65 years of age, it was reported that only around $29 \%$ of patients had large FB obstructions with a delaying diagnosis of between 1 and 3 months while in more than $80 \%$ of the aspiration episodes the foreign object was food (Lin et al. 2014).

A considerable proportion of aspirations syndrome cases is caused by noninfectious microaspiration, which is frequently caused by gastric reflux disease. Chronic microaspiration is also considered as a factor in the development of pulmonary fibrosis. Microaspirations of foreign substances, such as chronic lipoid pneumonia, provide the most compelling evidence (DiBardino and Wunderink 2015, Miller et al. 2005, Tobin et al. 1998).

The diagnosis of aspiration pneumonia depends mainly on the history of disease, medical history, vital 
signs and chest radiography. Most often, x-ray investigation reveals a new infiltration in a dependency pulmonary segment. In bed-bound patients, the reverse segments of upper lobes and upper segments of the lower lobes are the dependent pulmonary segments, while lower lobes, especially right, are traditionally affected in ambulatory patients (Bartlett and Gorbach 1975, Marik 2001). Dyspnea with a quick onset, hypoxemia, fever and radiological identification of any bilateral infiltrates or lung auscultation crackles in a hospitalized patient are the most common clinical variables in the diagnosis of aspiration pneumonia (Sanivarapu and Gibson 2021).

Clinical features can help to differentiate aspiration from pneumonitis and pneumonia. In contrast with chemical pneumonitis, the suction event is rarely seen in aspiration pneumonia (Bartlett and Gorbach 1975). Usually, the large amount of gastric content needed for chemical pneumonitis makes it more apparent. Furthermore, hyperacute hypoxemia occurs almost immediately (within hours) as a clinical course of chemical pneumonitis and results in either devastating lung injury or resolution within 48 hours. Patients also have bronchospasm, a frothy sputum, and infiltrates on chest x-ray, including non-dependent areas (Bartlett and Gorbach 1975, Doyle et al. 1995, Marik 2001, Mendelson 1946). However, there is no gold standard for distinguishing between these two aspiration events. One option to differentiate aspiration pneumonia and aspiration pneumonitis is to evaluate the level of serum procalcitonin as an appropriate biomarker. Indeed, the serum concentration of procalcitonin increases under various bacterial and viral infections (El-Solh et al. 2011, Son et al. 2017).

On the chest $\mathrm{x}$-ray, the changes in the right lower lobe are most frequently involved. Patients who have aspirated while upright may have bilateral lower lobe involvement while patients lying in the left lateral decubitus position tend to have left-sided infiltrates. The involvement of the right upper lobe is more common in patients who aspirate in the prone position and those with alcohol use disorder (Sanivarapu and Gibson 2021). Bronchoscopy can identify the aspirated food particles and also enables the retrieval of aspirate sample to be used for microbiological investigation.

\section{Pulmonary aspiration in critically ill patients}

Recognition of ARDS is quite low, with slightly more than half of those with mild ARDS and almost $80 \%$ of those with severe ARDS. ARDS is exceedingly common in critically ill patients and, as a result, it is not well understood or treated (A. Matthay et al. 2019). The study involving a multicenter treatment and the evaluation of the outcomes among critically ill patients with aspiration syndromes was conducted (Kane-Gill et al. 2007). The risk factors in critically ill patients include impaired consciousness, nasogastric and endotracheal intubation, improper positioning, anesthesia, neurological disorder, alcoholism, the overdose of drugs, and dysfunction of gastrointestinal motility (Kane-Gill et al. 2007, Miller et al. 2005). The results showed that patients with severe illnesses are more likely to develop aspiration pneumonia, and patients with multilobular aspiration pneumonia have a $90 \%$ mortality rate compared to only one lobe aspiration. Complications related to aspiration infections are not typical, and patients who do not have the symptoms within two hours following the aspiration are not likely to develop further respiratory problems (Kane-Gill et al. 2007).

The treatment involved a prescription of antimicrobial therapy for $97 \%$ of the aspirationsuspected patients, and for $100 \%$ of the confirmed pneumonia patients, while $38 \%$ of the patients with suspected suction and $52 \%$ of the patients with aspiration pneumonia were given combination of antibiotics (Huppert et al. 2019, Kane-Gill et al. 2007). However, antimicrobial therapy for aspiration pneumonia should be carefully considered depending on the aspiration site and type of hospital- or community-acquired pneumonia (Lionel et al. 2003). Inappropriate use of antimicrobials includes an increased risk of resistant pathogens being acquired, causing secondary infections, such as vancomycin-resistant Enterococci and Clostridium difficile-associated disease, and elevates drug-related costs (Kane-Gill et al. 2007, Muto et al. 2005). Antimicrobial prescribing is often unnecessarily broad, what raises a concern for the development of bacterial resistance.

Other complication in critically-ill patients is a post-extubation dysphagia (Brodsky et al. 2020). Identification of patients at risk of swallowing impairments and implementation of screening tools for dysphagia and aspiration should be the top priority in ICU patients (Brodsky et al. 2016, O’Horo et al. 2015).

\section{Treatment and management of aspiration syndromes}

Prior to attempting to discern between aspiration pneumonitis and pneumonia, it is critical to provide 
a prompt care depending on the symptomatology and course of the disease. However, the treatment is distinct for the two aspiration events and consists of supportive management for aspiration pneumonitis and antimicrobial therapy for aspiration pneumonia (Raghavendran et al. 2011, Son et al. 2017).

Although the data from randomized clinical trials concerning a certain therapy for aspiration are limited, there are some recommended guidelines in the handling of those patients If an aspiration occurs, the patient should be positioned so that the aspiration for any gastric content is reduced (Raghavendran and Napolitano 2011). The head should be turned laterally to allow a suction from the pharyngeal and oral cavity for patients who are awake. The patient's bed can also be raised with the head upward by a 45-degree angle. Any decision on intubation shall be based on the hypoxia level, neurological status and hemodynamic stability of the patient (Matthay et al. 2012, Raghavendran and Napolitano 2011). However, intubation may be required for those patients who have high volume particulate aspiration to facilitate future bronchoscopy (Moore et al. 2002). Nebulized bronchodilators may be given in the case of bronchospasm. Mechanical ventilation must continue following the current standards for lung protection strategies. Other interventions to prevent recurring gastric aspiration events, such as placing nasogastric tubes and connecting gastronomic tubes with suction or gravity drainage, should be introduced (Raghavendran and Napolitano 2011).

The role of the bronchoscopy is significant, however, aspirated material is often liquid and disperses rapidly. Hence, routine bronchoscopy with lavage is unlikely to prove useful. Contrary, if the aspirate is predominantly particulate, with clear radiographic evidence of lobar collapse or major atelectasis, a therapeutic bronchoscopy may prove helpful (Raghavendran et al. 2011). If a large amount of gastric content is aspirated, bronchoscopy can be used to remove the aspirated gastric fluid and solid material from the central airways, minimizing the inflammatory reaction, preventing atelectasis, and lowering the risk of infection (Marik 2001). In addition, bronchoscopy has the benefit of being able to take a sample of material from the lower part of the respiratory tract. Bacteriological investigation of BAL sample can help to guide a definitive therapy, as well as can allow a discontinuation of antibiotics administration if the cultures do not demonstrate significant bacterial growth (Kollef et al. 1995, Matthay et al. 2012, Raghavendran and Napolitano 2011).

In addition, the role of empirical antibiotics for aspiration management is examined. It was shown that the first-time aspiration occurs as a type of acute pneumonitis, a typical episode of inflammation accompanied by leukocytosis and fever. Although the treatment of aspiration pneumonitis does not require the use of antibiotics, pneumonia can hardly be distinguished (Marik 2001). Although there are no randomized clinical trials in the context of treating ventilator-associated pneumonia (VAP), a short course of antibiotics has not been shown to have adverse effects as long as the antibiotics are de-escalated or discontinued based on quantitative microbiology (Raghavendran et al. 2011, Rebuck et al. 2001). As a rational strategy in VAP, antibiotics administration may begin and then with the ICU duration it may be reduced. Emphasis is placed on the equal importance of antibiotics elimination, where the culture does not demonstrate a bacterial growth that is significant or that the aspirated material was contaminated (Matthay et al. 2012). There should also be considerations to the use of antibiotics in those patients with the aspiration event and simultaneously with the obstruction of the bowel or colonized gastric content (Matthay et al. 2019).

The antibiotic therapy is concentrated on the possible pathogens aspirated by a patient, determining that the site was acquired and considering resistant pathogens. However, seriously ill patients get treatment for the risks of dental health and multidrug resistance (Mandell and Niederman 2019). Patients with poor dental health should be considered and clindamycin specifically recommended for patients with pulmonary abscess or lung necrotization should be given (Matthay et al. 2019). Application of amoxicillin-clavulanate, moxifloxacin, levofloxacin or clindamycin may be given orally, specifically it is recommended for community-acquired pneumonia (Mandell and Niederman 2019). However, intravenous linezolid or vancomycin administration is recommended in hospitalized patients. Oral administration may be used in some patients with methicillin-resistant $S$. aureus respiratory or nasal colonization (Constantin et al. 2019). Routine antibiotic therapy is suggested only when suspected bacterial infection is present and when bronchoscopic cultures are negative, discontinuation is recommended. There is a number of antibiotic therapy management strategies. Medications for antibiotic treatment of aspiration pneumonia are listed in Table 3. 
Table 3. Antibiotics (dose, schedule, administration route) used in the treatment of aspiration pneumonia for patients with normal renal function (adjusted according to Mandall and Niederman 2019).

\begin{tabular}{ll}
\hline Antibiotic & Dose, Schedule, Administration route \\
\hline Ampicillin-sulbactam & $1.5-3 \mathrm{~g}$ every $6 \mathrm{~h}$, intravenous \\
Amoxicillin-clavulanate & $875 \mathrm{mg}$ twice daily, oral \\
Piperacillin-tazobactam & $4.5 \mathrm{~g}$ every $8 \mathrm{~h}$ or $3.375 \mathrm{~g}$ every $6 \mathrm{~h}$, intravenous \\
Ceftriaxone & $1-2 \mathrm{~g}$ once daily, intravenous \\
Cefepime & $2 \mathrm{~g}$ every $8-12 \mathrm{~h}$, intravenous \\
Ertapenem & $1 \mathrm{~g}$ once daily, intravenous \\
Imipenem & $500 \mathrm{mg}$ every $6 \mathrm{~h}$ or $1 \mathrm{~g}$ every $8 \mathrm{~h}$, intravenous \\
Meropenem & $1 \mathrm{~g}$ every $8 \mathrm{~h}$, intravenous \\
Levofloxacin & $750 \mathrm{mg}$ once daily, intravenous or oral \\
Moxifloxacin & $400 \mathrm{mg}$ once daily, intravenous or oral \\
Clindamycin & $450 \mathrm{mg} 3 / 4$ times daily, oral; or $600 \mathrm{mg}$ every $8 \mathrm{~h}$, i.v. \\
Gentamicin or tobramycin $\dagger$ & $5-7 \mathrm{mg} / \mathrm{kg}$ once daily, intravenous \\
Amikacin $\dagger$ & $15 \mathrm{mg} / \mathrm{kg}$ once daily, intravenous \\
Colistin ${ }^{\dagger}$ & $9 \mathrm{million}$ IU per day in $2 / 3$ divided doses, i.v. \\
Vancomycin $\dagger$ & $15 \mathrm{mg} / \mathrm{kg}$ every $12 \mathrm{~h}$, intravenous \\
Linezolid & $600 \mathrm{mg}$ every $12 \mathrm{~h}$, intravenous or oral \\
\hline
\end{tabular}

† For gentamicin and tobramycin, the dose should be adjusted to a trough level of less than $1 \mathrm{mg}$ per litre, less than $4 \mathrm{mg}$ per litre for amikacin, and 10 to $15 \mathrm{~g}$ per millilitre for vancomycin. ₹ The loading dose is 6 million to 9 million IU.

Steroids are not recommended as they show no benefits. Moreover, one study revealed gram-negative pneumonia occurred at a higher rate in patients receiving steroids (Raghavendran et al. 2011, Wolfe et al. 1977).

\section{Prevention of aspiration pneumonia and pneumonitis}

The risk for chemical pneumonitis postoperative procedures can be minimized if patients are required not to eat anything for at least eight hours and not to drink any clear liquids for at least two hours before the surgical procedure (Mandell and Niederman 2019). Preventive effect may also has an avoidance of medications that may disrupt swallowing or that promote aspiration, including antipsychotic agents, sedatives, and antihistamines in high-risk patients (Herzig et al. 2017).

Patients who have swallowing disorders, such as those who have had a stroke, should be evaluated for swallowing and talking, oral, rather than enteric tube feeding, and be in the form of mechanical supplementary meals with thickened fluids instead of purified foods and thin liquids (Momosaki 2017). It is recommended that the patients with swallowing difficulty and dysphagia receive nutritional rehabilitation as well as early mobilization to ensure that aspiration pneumonia does not reoccur
(Constantin et al. 2019). The patients should receive an enteral feeding in a semirecumbent position to decrease a gastric aspiration risk. Patient with oropharyngeal dysphagia should be positioned with chin down and head turned to one side while feeding and to encourage swallowing of small volumes, multiple swallows, and coughing after each swallow (Macht et al. 2014).

There is no certainty about the use of nasogastric tubes for the prevention of aspiration pneumonia. Furthermore, research has indicated that gastric feeding is superior to postpyloric feeding (Mandell and Niederman 2019). Further, a meta-analysis of five randomized controlled trials involving nonventilated patients at risk for pneumonia showed that oral care with chlorhexidine or mechanical oral cleaning was effective in preventing pneumonia. However, chlorhexidine use is controversial and may be associated with increased mortality among ventilated patients, possibly as a result of the toxic effects of chlorhexidine in the lungs (Klompas et al. 2014, Mandell and Niederman 2019). The prevention for aspiration pneumonia can be also used for aspiration pneumonitis, but the differences between the two are indicated in terms of prevention because while there are the same steps, additional steps can be used for each. 


\section{Conclusion}

Aspiration syndromes and associated lung injury represent a complex health problem. Gross aspiration of liquid or particulate matter into lungs can result in severe lung injury and respiratory failure leading to hypoxemia. The initial lung injury is primarily caused by inflammatory mediators rather than bacterial infection. There is no gold standard for distinguishing between the aspiration syndromes. In general, aspiration pneumonitis is witnessed event caused by aspiration of sterile gastric content, whereas aspiration pneumonia is characterized by aspiration of colonized oropharyngeal material. Short summary of the differences in aspiration syndromes can be found in Table 4. The diagnosis should be considered in the appropriate clinical settings in patients with known risk factors for aspiration and characteristic clinical and radiographic findings. There are various clinical manifestations of microaspiration and macroaspiration, with larger aspiration volume causing more serious repercussions. Aspiration pneumonia is more frequent in hospitalized patients with dysphagia. Initial therapy for acute aspiration depends on a prompt recognition that aspiration has occurred and involves a treatment of acute hypoxemia and bronchospasm (Johnson and Hirsch, 2003). Prophylactic antimicrobial therapy is not effective in patients with acute aspiration pneumonitis, and instead, escalated antibiotic therapy is needed when macroaspiration occurs. Current treatment guidelines for aspiration pneumonia support an initial empirical

Table 4. Aspiration pneumonitis and aspiration pneumonia

\begin{tabular}{|c|c|c|}
\hline & ASPIRATION PNEUMONITIS & ASPIRATION PNEUMONIA \\
\hline Primary mechanism & Aspiration of sterile gastric contents & $\begin{array}{l}\text { Aspiration of colonized } \\
\text { oropharyngeal material }\end{array}$ \\
\hline Pathophysiology & Acute lung injury & $\begin{array}{l}\text { Acute pulmonary inflammatory } \\
\text { response }\end{array}$ \\
\hline Bacteriology & $\begin{array}{l}\text { Initially sterile, potential subsequent } \\
\text { bacterial infection }\end{array}$ & $\begin{array}{l}\text { Gram-positive, gram-negative, and } \\
\text { rarely anaerobic bacteria }\end{array}$ \\
\hline Main risk factors & Depressed level of consciousness & Dysphagia and gastric dysmotility \\
\hline Age group affected & $\begin{array}{l}\text { Regardless of age, usually young } \\
\text { people }\end{array}$ & Usually older people \\
\hline Aspiration event & Witnessed & Usually not witnessed \\
\hline Typical demonstration & $\begin{array}{l}\text { History of depressed level of } \\
\text { consciousness, and pulmonary } \\
\text { infiltrate and respiratory symptoms } \\
\text { develop }\end{array}$ & $\begin{array}{l}\text { Institutionalized patient with } \\
\text { dysphagia; clinical features of } \\
\text { pneumonia and an infiltrate in a } \\
\text { dependent bronchopulmonary } \\
\text { segment develop }\end{array}$ \\
\hline Clinical features & $\begin{array}{l}\text { No symptoms or symptoms ranging } \\
\text { from a non-productive cough to } \\
\text { tachypnoea, bronchospasm, bloody } \\
\text { or frothy sputum, and respiratory } \\
\text { distress } 2 \text { or } 5 \mathrm{~h} \text { after aspiration }\end{array}$ & $\begin{array}{l}\text { Tachypnoea, cough, and pneumonia } \\
\text { symptoms }\end{array}$ \\
\hline
\end{tabular}

antibiotic therapy pending culture results. As demonstrated in this review article, aspiration syndromes with rather high morbidity and mortality are still an important clinical issue. Therefore, the research in this field should continue to further elucidate the pathophysiology, and to improve the screening and treatment of aspiration syndromes.

\section{Conflict of Interest}

There is no conflict of interest.

\section{Acknowledgements}

This work was supported by projects APVV-15-0075 and VEGA 1/0004/21. Thanks to Daniela Mokra for proofreading the article. 


\section{References}

ABDULLA S. Pulmonary aspiration in perioperative medicine. Acta Anaesthesiol Belg 64: 1-13, 2013.

ALDRIDGE KJ, TAYLOR NF. Dysphagia is a common and serious problem for adults with mental illness: a systematic review. Dysphagia 27: 124-137, 2012. https://doi.org/10.1007/s00455-011-9378-5

ALMIRALL J, BOIXEDA R, DE LA TORRE MC, TORRES A. Aspiration pneumonia: A renewed perspective and practical approach. Respir Med 185: 106485, 2021. https://doi.org/10.1016/J.RMED.2021.106485

BARTLETT JG. How important are anaerobic bacteria in aspiration pneumonia: when should they be treated and what is optimal therapy. Infect Dis Clin North Am 27: 149-155, 2013. https://doi.org/10.1016/j.idc.2012.11.016

BARTLETT JG, GORBACH SL. The triple threat of aspiration pneumonia. Chest 68: 560-566, 1975. https://doi.org/10.1378/chest.68.4.560

BONTEN MJ, GAILLARD CA, VAN DER GEEST S, VAN TIEL FH, BEYSENS AJ, SMEETS HG, STOBBERINGH EE. The role of intragastric acidity and stress ulcus prophylaxis on colonization and infection in mechanically ventilated ICU patients. A stratified, randomized, double-blind study of sucralfate versus antacids. Am J Respir Crit Care Med 152: 1825-1834, 1995. https://doi.org/10.1164/ajrccm.152.6.8520743

BOYD M, WATKINS F, SINGH S, HAPONIK E, CHATTERJEE A, CONFORTI J, CHIN R JR. Prevalence of flexible bronchoscopic removal of foreign bodies in the advanced elderly. Age Ageing 38: 396-400, 2009. https://doi.org/10.1093/ageing/afp044

BRINKMANN V, REICHARD U, GOOSMANN C, FAULER B, UHLEMANN Y, WEISS DS, WEINRAUCH Y, ZYCHLINSKY A. Neutrophil extracellular traps kill bacteria. Science 303: 1532-1535, 2004. https://doi.org/10.1126/science.1092385

BRODSKY MB, NOLLET JL, SPRONK PE, GONZÁLEZ-FERNÁNDEZ M. Prevalence, pathophysiology, diagnostic modalities, and treatment options for dysphagia in critically ill patients. Am J Phys Med Rehabil 99: 1164-1170, 2020. https://doi.org/10.1097/PHM.0000000000001440

BRODSKY MB, SUITER DM, GONZÁLEZ-FERNÁNDEZ M, MICHTALIK HJ, FRYMARK TB, VENEDIKTOV R, SCHOOLING T. Screening accuracy for aspiration using bedside water swallow tests: a systematic review and meta-analysis. Chest 150: 148-63, 2016. https://doi.org/10.1016/j.chest.2016.03.059

CABRE M, SERRA-PRAT M, PALOMERA E, ALMIRALL J, PALLARES R, CLAVÉ P. Prevalence and prognostic implications of dysphagia in elderly patients with pneumonia. Age Ageing 39: 39-45, 2010. https://doi.org/10.1093/ageing/afp100

CALKOVSKA A, MOKRA D, CALKOVSKY V, MATASOVA K, ZIBOLEN M. Clinical considerations when treating neonatal aspiration syndromes. Expert Rev Respir Med 13: 193-203, 2019. https://doi.org/10.1080/17476348.2019.1562340

CONSTANTIN JM, JABAUDON M, LEFRANT JY, JABER S, QUENOT JP, LANGERON O, et al. Personalised mechanical ventilation tailored to lung morphology versus low positive end-expiratory pressure for patients with acute respiratory distress syndrome in France (the LIVE study): a multicentre, single-blind, randomised controlled trial. Lancet Respir Med 7: 870-880, 2019. https://doi.org/10.1016/S2213-2600(19)30138-9

DAVIDSON BA, KNIGHT PR, HELINSKI JD, NADER ND, SHANLEY TP, JOHNSON KJ. The role of tumor necrosis factor-alpha in the pathogenesis of aspiration pneumonitis in rats. Anesthesiology 91: 486-499, 1999. https://doi.org/10.1097/00000542-199908000-00024

DAVIDSON BA, KNIGHT PR, WANG Z, CHESS PR, HOLM BA, RUSSO TA, HUTSON A, NOTTER RH. Surfactant alterations in acute inflammatory lung injury from aspiration of acid and gastric particulates. Am $\mathrm{J}$ Physiol Lung Cell Mol Physiol 288: L699-L708, 2005. https://doi.org/10.1152/ajplung.00229.2004

DELEGGE MH. Aspiration pneumonia: incidence, mortality, and at-risk populations. JPEN J Parenter Enteral Nutr 26: S19-S24; discussion S24-S25, 2002. https://doi.org/10.1177/014860710202600604

DIBARDINO DM, WUNDERINK RG. Aspiration pneumonia: A review of modern trends. J Crit Care 30: 40-48, 2015. https://doi.org/10.1016/J.JCRC.2014.07.011

DICKSON RP, ERB-DOWNWARD JR, HUFFNAGLE GB. The role of the bacterial microbiome in lung disease. Expert Rev Respir Med 7: 245-257, 2013. https://doi.org/10.1586/ers.13.24 
DIKENSOY O, USALAN C, FILIZ A. Foreign body aspiration: clinical utility of flexible bronchoscopy. Postgrad Med J 78: 399-403, 2002. https://doi.org/10.1136/pmj.78.921.399

DOYLE RL, SZAFLARSKI N, MODIN GW, WIENER-KRONISH JP, MATTHAY MA. Identification of patients with acute lung injury: Predictors of mortality. Am J Respir Crit Care Med 152: 1818-1824, 1995. https://doi.org/10.1164/ajrccm.152.6.8520742

DRAGAN V, WEI Y, ELLIGSEN M, KISS A, WALKER SAN, LEIS JA. Prophylactic Antimicrobial Therapy for Acute Aspiration Pneumonitis. Clin Infect Dis 67: 513-518, 2018. https://doi.org/10.1093/cid/ciy120

EIJKING EP, GOMMERS D, SO KL, VERGEER M, LACHMANN B. Surfactant treatment of respiratory failure induced by hydrochloric acid aspiration in rats. Anesthesiology 78: 1145-1151, 1993. https://doi.org/10.1097/00000542-199306000-00019

EL-SOLH AA, VORA H, KNIGHT PR 3RD, PORHOMAYON J. Diagnostic use of serum procalcitonin levels in pulmonary aspiration syndromes. Crit Care Med 39: 1251-1256, 2011. https://doi.org/10.1097/CCM.0b013e31820a942c

FANELLI V, VLACHOU A, GHANNADIAN S, SIMONETTI U, SLUTSKY AS, ZHANG H. Acute respiratory distress syndrome: new definition, current and future therapeutic options. J Thorac Dis 5: 326-334, 2013. https://doi.org/10.3978/j.issn.2072-1439.2013.04.05

FENG M-C, LIN Y-C, CHANG Y-H, CHEN C-H, CHIANG H-C, HUANG L-C, FENG MC, LIN YC, CHANG YH, CHEN CH, CHIANG HC, HUANG LC, YANG YH, HUNG CH. The mortality and the risk of aspiration pneumonia related with dysphagia in stroke patients. J Stroke Cerebrovasc Dis 28: 1381-1387, 2019. https://doi.org/10.1016/j.jstrokecerebrovasdis.2019.02.011

FOLKESSON HG, MATTHAY MA, HÉBERT CA, BROADDUS VC. Acid aspiration-induced lung injury in rabbits is mediated by interleukin-8-dependent mechanisms. J Clin Invest 96: 107-116, 1995. https://doi.org/10.1172/JCI118009

GOLDMAN G, WELBOURN R, KLAUSNER JM, KOBZIK L, VALERI CR, SHEPRO D, HECHTMAN HB. Leukocytes mediate acid aspiration-induced multiorgan edema. Surgery 114: 13-20, 1993.

GRIECO DL, MAGGIORE SM, ROCA O, SPINELLI E, PATEL BK, THILLE AW, BARBAS CSV, DE ACILU MG, CUTULI SL, BONGIOVANNI F, AMATO M, FRAT JP, MAURI T, KRESS JP, MANCEBO J, ANTONELLI M. Non-invasive ventilatory support and high-flow nasal oxygen as first-line treatment of acute hypoxemic respiratory failure and ARDS. Intensive Care Med Intensive 47: 851-866, 2021. https://doi.org/10.1007/s00134-021-06459-2

HACKETT AP, TRINICK RE, ROSE K, FLANAGAN BF, MCNAMARA PS. Weakly acidic pH reduces inflammatory cytokine expression in airway epithelial cells. Respir Res 17: 82, 2016. https://doi.org/10.1186/s12931-016-0399-3

HEMING TA, DAVÉ SK, TUAZON DM, CHOPRA AK, PETERSON JW, BIDANI A. Effects of extracellular pH on tumour necrosis factor-alpha production by resident alveolar macrophages. Clin Sci (Lond) 101: 267-274, 2001.

HERZIG SJ, LASALVIA MT, NAIDUS E, ROTHBERG MB, ZHOU W, GURWITZ JH, et al. Antipsychotics and the risk for aspiration pneumonia in non- psychiatric hospitalized patients: A cohort study. J Am Geriatr Soc 65: 2580-2586, 2017. https://doi.org/10.1111/jgs.15066.Antipsychotics

HOLLAAR V, VAN DER MAAREL-WIERINK C, VAN DER PUTTEN G-J, VAN DER SANDEN W, DE SWART B, DE BAAT C. Defining characteristics and risk indicators for diagnosing nursing home-acquired pneumonia and aspiration pneumonia in nursing home residents, using the electronically-modified Delphi Method. BMC Geriatr 16: 60, 2016. https://doi.org/10.1186/s12877-016-0231-4

HUNT EB, SULLIVAN A, GALVIN J, MACSHARRY J, MURPHY DM. Gastric aspiration and its role in airway inflammation. Open Respir Med J 12: 1-10, 2018. https://doi.org/10.2174/1874306401812010001

HUPPERT LA, MATTHAY MA, WARE LB. Pathogenesis of Acute Respiratory Distress Syndrome. Semin Respir Crit Care Med 40: 31-39, 2019. https://doi.org/10.1055/s-0039-1683996

HUXLEY EJ, VIROSLAV J, GRAY WR, PIERCE AK. Pharyngeal aspiration in normal adults and patients with depressed consciousness. Am J Med 64: 564-568, 1978. https://doi.org/10.1016/0002-9343(78)90574-0 
IBRAHIM SERSAR S, HAMZA UA, ABDELHAMEED WA, ABULMAATY RA, GOWAELI NN, MOUSSA SA, ALMORSI SM, HAFEZ MM. Inhaled foreign bodies: management according to early or late presentation. Eur J Cardio-Thoracic Surg 28: 369-374, 2005. https://doi.org/10.1016/j.ejcts.2005.05.013

JOHNSON JL, HIRSCH CS. Aspiration pneumonia. Recognizing and managing a potentially growing disorder. Postgrad Med 113: 99-102,105-106,111-112, 2003. https://doi.org/10.3810/pgm.2003.03.1390

KANE-GILL SL, OLSEN KM, REBUCK JA, REA RS, BOATWRIGHT DW, SMYTHE MA, WALKER TR, LAGER SL, HODGMAN T; ASPIRATION EVALUATION GROUP OF THE CLINICAL PHARMACY AND PHARMACOLOGY SECTION. Multicenter treatment and outcome evaluation of aspiration syndromes in critically ill patients. Ann Pharmacother 41: 549-555, 2007. https://doi.org/10.1345/aph.1H675

KENNEDY TP, JOHNSON KJ, KUNKEL RG, WARD PA, KNIGHT PR, FINCH JS. Acute acid aspiration lung injury in the rat: biphasic pathogenesis. Anesth Analg 69: 87-92, 1989.

KLOMPAS M, SPECK K, HOWELL MD, GREENE LR, BERENHOLTZ SM. Reappraisal of routine oral care with chlorhexidine gluconate for patients receiving mechanical ventilation: Systematic review and meta-analysis. JAMA Intern Med 174: 751-761, 2014. https://doi.org/10.1001/jamainternmed.2014.359

KNIGHT PR, DAVIDSON BA, NADER ND, HELINSKI JD, MARSCHKE CJ, RUSSO TA, HUTSON AD, NOTTER RH, HOLM BA. Progressive, severe lung injury secondary to the interaction of insults in gastric aspiration. Exp Lung Res 30: 535-557, 2004. https://doi.org/10.1080/01902140490489162

KNIGHT PR, RUTTER T, TAIT AR, COLEMAN E, JOHNSON K. Pathogenesis of gastric particulate lung injury: a comparison and interaction with acidic pneumonitis. Anesth Analg 77: 754-760, 1993. https://doi.org/10.1213/00000539-199310000-00017

KOLLEF MH, BOCK KR, RICHARDS RD, HEARNS ML. The safety and diagnostic accuracy of minibronchoalveolar lavage in patients with suspected ventilator-associated pneumonia. Ann Intern Med 122: 743-748, 1995. https://doi.org/10.7326/0003-4819-122-10-199505150-00002

KOSUTOVA P, MIKOLKA P, BALENTOVA S, ADAMKOV M, MOKRA D. Effects of nitric oxide donor on the lung functions in a saline lavage-induced model of ARDS. Physiol Res 68: S265-S273, 2019. https: /doi.org/10.33549/physiolres. 934365

LANGMORE SE, TERPENNING MS, SCHORK A, CHEN Y, MURRAY JT, LOPATIN D, LOESCHE WJ. Predictors of aspiration pneumonia: how important is dysphagia? Dysphagia 13: 69-81, 1998. https://doi.org/10.1007/PL00009559

LIAPIKOU A, POLVERINO E, CILLONIZ C, PEYRANI P, RAMIREZ J, MENENDEZ R, et al. A worldwide perspective of nursing home-acquired pneumonia compared with community-acquired pneumonia. Respir Care 59: 1078-85, 2014. https://doi.org/10.4187/respcare.02788

LIMPER AH, PRAKASH UB. Tracheobronchial foreign bodies in adults. Ann Intern Med 112: 604-609, 1990. https://doi.org/10.7326/0003-4819-112-8-604

LIN L, LV L, WANG Y, ZHA X, TANG F, LIU X. The clinical features of foreign body aspiration into the lower airway in geriatric patients. Clin Interv Aging 9: 1613-1618, 2014. https://doi.org/10.2147/CIA.S70924

LINDENAUER PK, STRAIT KM, GRADY JN, NGO CK, PARISI ML, METERSKY M, et al. Variation in the diagnosis of aspiration pneumonia and association with hospital pneumonia outcomes. Ann Am Thorac Soc 15: 562-569, 2018. https://doi.org/10.1513/AnnalsATS.201709-7280C

LIONEL A. MANDELL, JOHN G. BARTLETT, SCOTT F. DOWELL, THOMAS M. FILE, JR., DANIEL M. MUSHER AND CW. Update of practice guidelines for the management of community-acquired pneumonia in immunocompetent adults. Infect Dis Clin Pract 37: 1405-1433, 2003. https://doi.org/10.1086/380488

MACHT M, WHITE SD, MOSS M. Swallowing dysfunction after critical illness. Chest 146: 1681-1689, 2014. https://doi.org/10.1378/chest.14-1133

MANDELL LA, NIEDERMAN MS. Aspiration pneumonia. N Engl J Med 380: 651-663, 2019. https://doi.org/10.1056/NEJMra1714562

MARIK PE. Aspiration pneumonitis and aspiration pneumonia. $N$ Engl J Med 344: 665-671, 2001. https://doi.org/10.1056/NEJM200103013440908

MARIK PE, KAPLAN D. Aspiration pneumonia and dysphagia in the elderly. Chest 124: 328-336, 2003. https://doi.org/10.1378/chest.124.1.328 
MARRARO GA, LUCHETTI M, SPADA C, GALASSINI E, GIOSSI M, PIERO AMP. Selective medicated (normal saline and exogenous surfactant) bronchoalveolar lavage in severe aspiration syndrome in children. Pediatr Crit Care Med 8: 476-481, 2007. https://doi.org/10.1097/01.PCC.0000282158.09783.7C

MATTHAY A, HACKETT J, SHANKAR-HARI M. ARDS Subphenotypes and Differential Response to Simvastatin: Secondary Analysis of a Randomized Controlled Trial 6: 691-698, 2019. https://doi.org/10.1016/S22132600(18)30177-2.ARDS

MATTHAY MA, WARE LB ZG. The acute respiratory distress syndrome. TThe J Clin Investig 122: 2731-2740, 2012. https://doi.org/10.1016/j.molmed.2013.08.004

MATTHAY MA, ZEMANS RL, ZIMMERMAN GA, ARABI YM, BEITLER JR, MERCAT A, HERRIDGE M, RANDOLPH AG, CALFEE CS. Acute respiratory distress syndrome. Nat Rev Dis Prim 5: 18, 2019. https://doi.org/10.1038/s41572-019-0069-0

MENDELSON CL. The aspiration of stomach contents into the lungs during obstetric anesthesia. Am J Obstet Gynecol 52: 191-205, 1946. https://doi.org/10.1016/S0002-9378(16)39829-5

METHENY NA, CLOUSE RE, CHANG Y-H, STEWART BJ, OLIVER DA, KOLLEF MH. Tracheobronchial aspiration of gastric contents in critically ill tube-fed patients: frequency, outcomes, and risk factors. Crit Care Med 34: 1007-1015, 2006. https://doi.org/10.1097/01.CCM.0000206106.65220.59

MIKOLKA P, CURSTEDT T, FEINSTEIN R, LARSSON A, GRENDAR M, RISING A, et al. Impact of synthetic surfactant CHF5633 with SP-B and SP-C analogues on lung function and inflammation in rabbit model of acute respiratory distress syndrome. Physiol Rep 9, 2021. https://doi.org/10.14814/phy2.14700

MIKOLKA P, KOSUTOVA P, KOLOMAZNIK M, TOPERCEROVA J, KOPINCOVA J, CALKOVSKA A, et al. Effect of different dosages of dexamethasone therapy on lung function and inflammation in an early phase of acute respiratory distress syndrome model. Physiol Res 68: S253-S263, 2019. https://doi.org/10.33549/physiolres.934364

MILLER CD, REBUCK JA, AHERN JW, ROGERS FB. Daily Evaluation of Macroaspiration in the Critically Ill Post-trauma Patient. Curr Surg 62: 504-508, 2005. https://doi.org/10.1016/J.CURSUR.2005.03.003

MOKRÁ D. Acute lung injury - from pathophysiology to treatment. Physiol Res 69: S353-S366, 2020. https://doi.org/10.33549/physiolres.934602

MOMOSAKI R. Rehabilitative management for aspiration pneumonia in elderly patients. J Gen Fam Med 18: 12-15, 2017. https://doi.org/10.1002/jgf2.25

MONTANA A, SALERNO M, FEOLA A, ASMUNDO A, DI NUNNO N, CASELLA F, et al. Risk management and recommendations for the prevention of fatal foreign body aspiration: four cases aged 1.5 to 3 years and mini-review of the literature. Int J Environ Res Public Health 17: 2020. https://doi.org/10.3390/ijerph17134700

MOORE FA, MCCLAVE, MOORE, HEYLAND, DELEGGE. Treatment of aspiration in intensive care unit patients. J Parenter Enter Nutr 26: 69-74, 2002. https://doi.org/10.1177/014860710202600611

MUTO CA, POKRYWKA M, SHUTT K, MENDELSOHN AB, NOURI K, POSEY K, ROBERTS T, CROYLE K, KRYSTOFIAK S, PATEL-BROWN S, PASCULLE AW, PATERSON DL, SAUL M HL. Clostridium d iffi cile a ssociated $\mathrm{d}$ isease: Diagnosis and $\mathrm{t}$ reatment. Infect Control Hosp Epidemiol 26: 273-280, 2005. https://doi.org/10.1086/502539

MYLOTTE JM, GOODNOUGH S, NAUGHTON BJ. Pneumonia versus aspiration pneumonitis in nursing home residents: diagnosis and management. J Am Geriatr Soc 51: 17-23, 2003a. https://doi.org/10.1034/j.16015215.2002.51004.x

MYlotTe JM, GOODNOUGH S, NAUGHTON BJ. Pneumonia versus aspiration pneumonitis in nursing home residents: diagnosis and management. J Am Geriatr Soc 51: 17-23, 2003. https://doi.org/10.1034/j.16015215.2002.51004.x

NASON KS. Acute intraoperative pulmonary aspiration. Thorac Surg Clin 25: 301-307, 2015. https://doi.org/10.1016/j.thorsurg.2015.04.011

NEILL S, DEAN N. Aspiration pneumonia and pneumonitis: a spectrum of infectious/noninfectious diseases affecting the lung. Curr Opin Infect Dis 32: 152-157, 2019. https://doi.org/10.1097/QCO.0000000000000524 
NISHIZAWA H, YAMADA H, MIYAZAKI H, OHARA M, KANEKO K, YAMAKAWA T, WIENER-KRONISH J, KUDOH I. Soluble complement receptor type 1 inhibited the systemic organ injury caused by acid instillation into a lung. Anesthesiology 85: 1120-1128, 1996. https://doi.org/10.1097/00000542-199611000-00021

O'HORO JC, ROGUS-PULIA N, GARCIA-ARGUELLO L, ROBBINS J, SAFDAR N. Bedside diagnosis of dysphagia: a systematic review. J Hosp Med 10: 256-265, 2015. https://doi.org/10.1002/jhm.2313

ORTEGA FERNÁNDEZ O, CLAVÉ P. Oral hygiene, aspiration, and aspiration pneumonia: from pathophysiology to therapeutic strategies. Curr Phys Med Rehabil Reports 1: 292-295, 2013. https://doi.org/10.1007/s40141-013$\underline{0032-z}$

PAINTAL HS, KUSCHNER WG. Aspiration syndromes: 10 clinical pearls every physician should know. Int J Clin Pract 61: 846-852, 2007. https://doi.org/10.1111/j.1742-1241.2007.01300.x

PERBET S, MONGARDON N, DUMAS F, BRUEL C, LEMIALE V, MOURVILLIER B, et al. Early-onset pneumonia after cardiac arrest: characteristics, risk factors and influence on prognosis. Am J Respir Crit Care Med 184: 1048-1054, 2011. https://doi.org/10.1164/rccm.201102-03310C

PETROIANNI A, CECCARELLI D, CONTI V, TERZANO C. Aspiration pneumonia. Pathophysiological aspects, prevention and management. A review. Panminerva Med 48: 231-239, 2006

RAFANAN AL, MEHTA AC. ADULT AIRWAY FOREIGN BODY REMOVAL: What's New? Clin Chest Med 22: 319-330, 2001. https://doi.org/10.1016/S0272-5231(05)70046-0

RAGHAVENDRAN K, NAPOLITANO LM. Definition of ALI/ARDS. Crit Care Clin 27: 429-437, 2011. https://doi.org/10.1016/j.ccc.2011.05.006

RAGHAVENDRAN K, NEMZEK J, NAPOLITANO LM, KNIGHT PR. Aspiration-induced lung injury. Crit Care Med 39: 818-826, 2011. https://doi.org/10.1097/CCM.0b013e31820a856b

RANDELL SH, BOUCHER RC. Effective mucus clearance is essential for respiratory health. Am J Respir Cell Mol Biol 35: 20-28, 2006. https://doi.org/10.1165/rcmb.2006-0082SF

REBUCK JA, RASMUSSEN JR, OLSEN KM. Clinical aspiration-related practice patterns in the intensive care unit: a physician survey 29: 2239-2244, 2001. https://doi.org/10.1097/00003246-200112000-00001

REEVES EP, LU H, JACOBS HL, MESSINA CGM, BOLSOVER S, GABELLA G, POTMA EO, WARLEY A, ROES J, SEGAL AW. Killing activity of neutrophils is mediated through activation of proteases by $\mathrm{K}+$ flux. Nature 416: 291-297, 2002. https://doi.org/10.1038/416291a

ROTSTEIN C, EVANS G, BORN A, GROSSMAN R, LIGHT RB, MAGDER S, MCTAGGART B, WEISS K, ZHANEL GG. Clinical practice guidelines for hospital-acquired pneumonia and ventilator-associated pneumonia in adults. Can J Infect Dis Med Microbiol 19: 19-53, 2008. https://doi.org/10.1155/2008/593289

SALIK I, DOHERTY TM. Mendelson Syndrome. In: StatPearls. Treasure Island (FL): StatPearls Publishing; June 26, 2021.

SANIVARAPU RR, GIBSON J. Aspiration Pneumonia. In: StatPearls. Treasure Island (FL): StatPearls Publishing, Treasure Island (FL): 2021.

SEGAL LN, ROM WN, WEIDEN MD. Lung microbiome for clinicians. New discoveries about bugs in healthy and diseased lungs. Ann Am Thorac Soc 11: 108-116, 2014. https://doi.org/10.1513/AnnalsATS.201310-339FR

SEHGAL IS, DHOORIA S, RAM B, SINGH N, AGGARWAL AN, GUPTA D, et al. Foreign body inhalation in the adult population: experience of 25,998 bronchoscopies and systematic review of the literature. Respir Care 60 : 1438-1448, 2015. https://doi.org/10.4187/respcare.03976

SHANLEY TP, DAVIDSON BA, NADER ND, BLESS N, VASI N, WARD PA, JOHNSON KJ, KNIGHT PR. Role of macrophage inflammatory protein-2 in aspiration-induced lung injury. Crit Care Med 28: 2437-2444, 2000. https://doi.org/10.1097/00003246-200007000-00041

SON YG, SHIN J, RYU HG. Pneumonitis and pneumonia after aspiration. J Dent Anesth Pain Med 17: 1-12, 2017. https://doi.org/10.17245/jdapm.2017.17.1.1

SPILKER CA, HINTHORN DR, PINGLETON SK. Intermittent enteral feeding in mechanically ventilated patients. The effect on gastric $\mathrm{pH}$ and gastric cultures. Chest 110: 243-248, 1996. https://doi.org/10.1378/chest.110.1.243

STUBINGTON TJ, KAMANI T. Food bolus and oesophageal foreign body: a summary of the evidence and proposed management process. Eur Arch Otorhinolaryngol 2021. https://doi.org/10.1007/s00405-020-06569-5 
TOBIN RW, POPE CE, PELLEGRINI CA, EMOND MJ, SILLERY J, RAGHU G. Increased prevalence of gastroesophageal reflux in patients with idiopathic pulmonary fibrosis. Am J Respir Crit Care Med 158: 1804-8, 1998. https://doi.org/10.1164/ajrccm.158.6.9804105

UMESAN UK, CHUA KL, BALAKRISHNAN P. Prevention and management of accidental foreign body ingestion and aspiration in orthodontic practice. Ther Clin Risk Manag 8: 245-252, 2012. https://doi.org/10.2147/TCRM.S30639

WARNER MA, WARNER ME, WEBER JG. Clinical significance of pulmonary aspiration during the perioperative period. Anesthesiology 78: 56-62, 1993. https://doi.org/10.1097/00000542-199301000-00010

WOLFE JE, BONE RC, RUTH WE. Effects of corticosteroids in the treatment of patients with gastric aspiration. Am J Med 63: 719-722, 1977. https://doi.org/10.1016/0002-9343(77)90157-7

ZALOGA GP. Aspiration-related illnesses: definitions and diagnosis. JPEN J Parenter Enteral Nutr 26: S2-S7, 2002, discussion S7-S8. https://doi.org/10.1177/014860710202600602 